\title{
Science Academies' Refresher Course in Mathematics
}

\section{1-14 June 2015}

\author{
at School of Mathematics, Shri Mata Vaishno Devi University \\ Katra, Jammu \& Kashmir
}

\author{
Sponsored by Indian Academy of Sciences, Bangalore, \\ Indian National Science Academy, New Delhi \\ The National Academy of Sciences, India, Allahabad
}

A two-week Refresher Course in Mathematics will be organized during 1-14 June 2015 at School of Mathematics, SMVD University, Katra, Jammu \& Kashmir in association with School of Innovation and Community Development, SMVDU. The aim of the Course is to display the beauty of "complex analysis" in a more interactive manner so that the participants can understand basics of the discussed topic which can be used in teaching to motivate undergraduate and postgraduate students.

Resource Persons: Professors Gadadhar Misra (IISc, Bangalore), Maddaly Krishna (IMSc, Chennai), B Ramakrishnan (HRI, Allahabad), HL Vasudeva (IISER, Mohali), Gautam Bharali (IISc, Bangalore), Sameer Chavan (IIT, Kanpur).

Course Director: Ajit Iqbal Singh

Course Coordinator: Ananga Kumar Das, SMVD University, Katra, J\&K.

Applications are invited for the Course from teachers who are teaching undergraduate and/or postgraduate courses in Mathematics. Research Scholars who are motivated to teach Mathematics in future may also apply. Local hospitality will be provided to all selected outstation participants. Actual travel expenses by $3 \mathrm{AC}$ train by the shortest route will also be reimbursed.

Interested applicants must submit their application online by clicking on the following link http://web-japps.ias.ac.in:8080/Refreshcourse/RCMA.jsp

A printed copy of the application form signed by the applicant along with a recent detailed CV must be sent through the Head of the Institution by speed post to the Course Coordinator: Dr A. K. Das, Director I/c, School of Mathematics, Shri Mata Vaishno Devi University, Katra-182320, Jammu \& Kashmir.

Last date of application (online mode): 25 March 2015

Last date for receipt of hard copy of the application: 30 March 2015.

For any query, please e-mail to: akdasdu@gmail.com

For details please visit: http://www.smvdu.net.in 